\title{
INTRODUCING ESD CONCEPTS INTO TEACHING EDUCATION PROGRAM
}

\author{
Lucia E.Yamamoto, Keiko Ikeda, and Akihito Nakajo
}

\begin{abstract}
In response to the new Basic Plan for Promotion of Education drawn by the Ministry of Education, Culture, Sports, Science and Technology, the Faculty of Education of Shizuoka University redefined its mission upholding target item such as education closely connected with community, and enhancing the level of teacher training from local, national and global perspective. Based on this new orientation, the faculty introduced class subject on ESD in the teacher education curricula, and in order to deepen students' understanding of ESD, the field trip (or Student Exchange Program) aimed to learn with/at community was also scheduled. In this paper, we introduce these two activities and explore their possibilities in enhancing educational practices in ESD. It is considered essential that in teaching ESD context the educator needs to,; a) building ownership on issues of creating a sustainable society, b) acquiring regional/local cognition positioning oneself as one of the stakeholders, c) understanding links between local and global issues. Enhancement of these skills and capacities will be discussed from the perspectives of; i) system of teacher education, ii) method of teaching and learning, iii) collaboration among university, schools, and community, iv) evaluation of qualifications and capacities.
\end{abstract}

\section{KEYWORD:}

ESD, System of Teacher Education, Method of Teaching and Learning

\section{INTRODUCTION}

The Faculty of Education of Shizuoka University redefined its mission in 2013, upholding target items such as "education closely connected with the community" and "enhancing the level of teacher training from local, national, and global perspectives." As a part of teacher training reforms based on these circumstances, the Faculty of Education at Shizuoka University launched the Working Group for Promotion of ESD and Internationalization in 2013 and has since been involved in the promotion of ESD for teacher training. This report is an early-stage discussion two years after the adoption of the program, looking at the challenges relating to fostering fundamental qualities and abilities necessary to build a sustainable society. In particular, we will describe in an organized manner the challenges that have been revealed in our efforts to enhance the following abilities in students: to have a sense of ownership regarding the issues in building a sustainable society; acquire proper knowledge of the area with the readiness to work to solve, as a member of the community, the issues; and to understand the connection between local and global issues.

\section{INITIATIVES By The FACULTY OF EDUCATION AT SHIZUOKA UNIVERSITY}

\author{
Introduction of ESD courses to faculty \\ curriculum
}

Starting in the academic year of 2014, courses related to ESD were newly established for the firstto third-year students. The class titles offered are: ESD and Issues in Contemporary Society for the first-, ESD Theories and Practice for the second-, and ESD and Practical Training for the third-year students. All of these were introduced as optional quasi teacher-training-related subjects.

This report discusses the course started in 2014 for first-year students: ESD and Issues in Contemporary Society (full year, four credits). The objectives of the course are to raise interest in ESD, to have the students acquire the skills and attitudes to communicate with others on issues in modern society and to cooperate with them in trying to solve these problems. To practice step-bystep learning toward such goals, the course was set for a full year, and student-led learning methods built upon problem-based learning (PBL) were also introduced. After attending classes on issues closely related to the creation of a sustainable society, the students participated in discussions 
and research, learned in a hands-on style, and completed the course after exploring the issues from an ESD perspective and proposed solutions in a report. Each of the students selected one of the seven challenges that were discussed in the course (environment, energy, multicultural coexistence, human rights and poverty, aging society with dwindling birth rate and the local community, multilingual environment, and development), by which they were divided into seven groups and deepened their learning.

\section{Community service learning courses at Gadjah Mada University in Indonesia}

A community service learning program has been implemented in cooperation with Gadjah Mada University, a national university in Indonesia, which has entered into an exchange agreement with the Faculty of Education of Shizuoka University. In the program, students of the two countries learn about each other's local issues through mutual visits. In August, our students spent around ten days attending practical lessons given by Gadjah Mada University in a suburban village near Jogjakarta City, Indonesia and went on field trips to observe how community are supported by the university. More specifically, the Japanese students examined the characteristics of resources for tourism in the area from the standpoint of developing sustainable tourism. They were also engaged in educational practice, health service, and other activities, and got handson learning at a site where knowledge and skills academically acquired are being given back to the area in accordance with its needs. Students from Gadjah Mada University, on the other hand, stayed in Japan in December for about ten days. They visited municipal government agencies and non-profit organizations that are striving for the development of sustainable tourism in Shizuoka Prefecture capitalizing on Mt. Fuji as their resource. Through their tourism experiences in Japan, the Indonesian students learned about the differences between Japan and Indonesia and also development methods adaptable to their country.

\section{Challenges and PRospects for THE PROMOTION OF ESD IN TEACHER TRAINING}

The ESD Implementation Plan states, "It is necessary that learners become aware of diverse issues, view these as their own, and act toward solutions". To this end, it is important for the individuals receiving education to work in a nearby community to develop implementation methods tailored for the local characteristics and promote them. That is to say, the essential qualities and abilities for those who work for the building of a sustainable society are, first and foremost, having a sense of ownership regarding the issue for achieving a sustainable society, and preparing to be a person responsible for settling the issues as a member of the community. Based on these assumptions, it is indispensable to be able to acquire proper awareness about the area and to understand the relationship between local and global issues.

These basic qualities and abilities are naturally important for teachers who are expected to practice ESD along with children, thus should be nurtured in teacher training. In the present situation, however, various challenges are present.

First of all, unfortunately not many students show interest or actually participate in the class subjects or student exchange program described above. The number of students who took the course of ESD and Issues in Contemporary Society was 13 students in 2014 and 21 students in 2015. Moreover, while the community service learning project through the student exchange program has set its maximum number of students as five, the number of applicants has not even reached this quota.

Most students have had the experience, during their school days including high school, of studying more than one topic among the variety of ESD learning tasks. In addition, students who took ESD-related courses expressed thoughts such as, "When I talked with three other classmates, it was the first time I was able to think deeply about multicultural coexistence," and "Now I would like to research the reality of the homelessness (poverty) on my own. I wished I could study further in a hands-on manner." These thoughts give a glimpse into these students' enthusiasm toward exploring the issues that they dealt with in the learning activities. Therefore, we do not regard them having no basic knowledge of the challenges in creating a sustainable society or no interest in them. We presume that they have not had experiences or opportunities to see the issues as their own, or their own community's and to actively learn or take actions. Furthermore, when it comes to a global issue where it is difficult to understand its relationships with issues occurring around them or in a familiar community, the students obviously had more difficulty in having a sense of ownership.

Certainly, education offered at a high school that complies with the current curriculum guideline 
focuses on individual fields with few opportunities to overlook them as a whole or considers links between an issue and another. This might have resulted in a reluctance to understanding the ESD philosophy or way of learning. It is said that, in response to this present situation, the next revision of the curriculum guidelines will contain two mandatory classes in high school geography and history: Integrated History, which studies the modern history of Japan and the world; and Integrated Geography, which nurtures the power to resolve local- and global-scale problems. We suspect that the ESD philosophy will be heavily reflected in the new subjects to be introduced in the restructuring of the high school curriculum.

To address such situation of students, how can we make them realize that they themselves have to acquire a sense of ownership and knowledge of the community, and enhance their level of understanding regarding the relationship between local and global issues? Hereafter we will organize and present what are thought to be necessary or effective in the following four segments: 1 . Teacher training system; 2 . Teaching and learning methods; 3. Cooperation with schools and communities; and 4. Evaluation of students' quality and ability.

\section{(i) Teacher training system}

The challenges pointed out in firmly incorporating the ESD-related content in the teacher-training curriculum are as follows: Merely listening to classroom lectures are not sufficient for learning about challenges for building a sustainable society and how to deal with them. Fieldwork and reporting activities would not fit in the time allotted for one class period. Yet intensive courses lasting several days are not likely to allow for good fieldwork and other activities. It is, therefore, necessary to adeptly devise a class timetable, such as one classroom lecture lasting for two class periods every other week. The teacher training department is not as flexible as others in scheduling timetable, so some special planning would be necessary. Moreover, as off-campus activities will increase, appropriate rules regarding insurance, transportation means, and the like will have to be formulated.

It is anticipated that the teachers themselves may encounter unfamiliar topics, which will produce a burden for them in terms of securing time to prepare for a class, let alone time for accompanying students in their fieldwork, learning activities, and particularly, exchange programs abroad. This problem has entailed the current situation where there are not many teachers who have experience or interest in practicing fieldwork. Teachers have been increasingly busier due to overwhelming administrative work, making overseas business trips for more than ten days becoming almost impossible. We have two teachers assigned taking shifts in fulfilling the duties of leading and assisting students who visit overseas universities that concluded exchange agreements with us. The number of teachers in the teacher training department who have experienced practicing fieldwork or who find it interesting is extremely limited in comparison to the humanities and social sciences departments. Considering that making business trips to rural villages in developing countries with poor communication environment poses a certain risk, it is a serious challenge to secure enough number of teachers who are capable of flexibility coping with the environment and carrying out their work.

\section{(ii) Teaching and learning methods}

Various learning methods have been tried out in ESD promotion initiatives. Seminarstyle lectures with a small number of people are given for this purpose, mainly employing active learning and service learning. ESD courses offer omnibus-style lectures and are taught by several teachers whose specialties vary among the ESDrelated subjects. Students taking this course are provided with opportunities to understand diverse challenges in multifaceted ways. In these activities and lectures, PBL format is adopted where students and participants form a team to explore challenges. Within a fixed time period, however, PBL method proved to be incapable of deepening students' awareness of the challenges. Devising desirable size and length of the classes/activities and planning curriculum with a long-term outlook is deemed necessary.

Challenges are also seen in understanding the community in classes regarding communities. When asked about different issues of the area or about the distribution of resources of his/ her own community, it was obvious that they did not have much recognition of a current state of affairs. What is first sought is training to deepen awareness of the students' sphere of daily life (familiar area), then honing this understanding to actually apply in other areas.

It was drawn from their participation in community service learning at Gadjah Mada University that what is required is developing the ability to understand the locality such as distribution situation of their resources and the means to leverage them. This is because there is no uniform way of sustainable tourism development, which is to make the best use of the unique 
community resources including their lifestyle maintained in the area as well as the environment, and the ideas utilized for this are to be based on a comprehension of the regional profile and specific characteristics.

Our challenge for the future is to make sure that students accumulate practical fieldwork experiences through ESD courses and put their skills into practice in other areas in Japan or abroad.

(iii) Cooperation with schools and communities

Students taking the ESD courses need to go out of the campus to deepen their understanding of current issues. They need to comprehend the circumstances of the issues and witness specific efforts being made. The students can thereby affirm where they stand, and recognize that the issues they have picked are their own. In short, practical training opportunities in the campus and local community are essential for ESD. Nevertheless, it is too great a burden on the faculty to coordinate these opportunities. We must secure sites of practical training not only by relying on the teachers' personal connection with the community but also by building links and collaborative relationships as an organization. As a partnership with schools and the community are hardly achieved in a top-down manner, it is important to maintain day-to-day contact with them to construct mutually beneficial relations.

\section{(iv) Evaluation of students' quality and ability}

Looking at the actual situations of students, we see many who study hard on limited-scope assignments given, but it takes time for them to acquire attitudes for independent learning. Although they have knowledge of issues in daily life or global issues to some extent, their curiosity and interest seem to be limited in range. It will be effective to come up with a way to organically connect the existing curriculum with the study of ESD courses, such as encouraging study from a global angle utilizing interdisciplinary courses.

Another problem remains of how to evaluate what students have learned. The conventional method of measuring and giving grades for the amount of knowledge acquired does not fit with PBL class format. As time is needed to discover problems and think about it to figure out possible solutions, assessing the long-term manifestation of students' learning is difficult. We include in our evaluation students' attitude that continues to transform throughout the course. Not only the completed works such as report exhibited, presentations, and implementation of cooperative problem solving that are ultimately evaluated, the process to get to the point should also be considered as an important part of their achievement.

\section{Looking Toward The Future}

Based on the experience accumulated in a short period of two years since ESD promotion in teacher training began, this report organized and presented the challenges in nurturing the fundamental qualities and abilities necessary to be a contributor to a sustainable society, including acquisition of a sense of ownership and knowledge of the area and understanding of the relationship between local and global issues.

Students are expected to acquire, under the tight schedule of the teacher training curriculum, a sense of ownership and knowledge of the area while also raising the level of knowledge in regards to various challenges accompanying ESD. In order to support the students to achieve this goal, we will be required to follow their changes with a long-term vision from the time of entering university until graduation and evaluate, rather than completing evaluation by each individual class or subject. To deepen students' learning in the PBL activities and classes performed in participation style, in addition to organically utilizing the current curriculum and practice opportunities available in the community, evaluation methods that place more importance on the process should be fully developed.

\section{REFERENCES}

UNESCO (2012). Education Sustaiable Development. Sourcebook. Paris France : the United Nations Educational, Scientific and Cultural Organization Publication.

UNESCO. 2006. Education for Sustainable Development Toolkit. Learning \& Training Tools No. 1. Available on line at http://unesdoc.unesco. org/images/0015/001524/ 152453eo.pdf Also available online in html at http:/ / www. esdtoolkit.org / reorient_edu / stoplight. htm

Schreiber, Jörg-Robert and Hannes Siege. (2016) Curriculum Framework Education for Sustainable Development. Bonn : Cornelsen, Engagement Global gGmbH publication 